
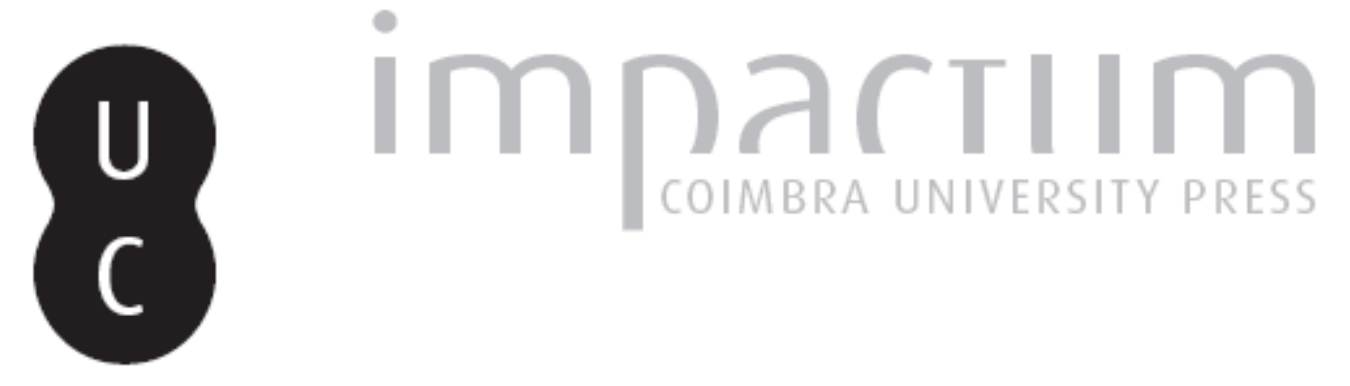

\title{
[Recensão a] Florio, R. (2011) transformaciones del héroe y el viaje heroico en el peristephanon de prudencio
}

Autor(es): Tola, Eleonora

Publicado por: Sociedade Brasileira de Estudos Clássicos

URL persistente:

URI:http://hdl.handle.net/10316.2/37156

DOI:

DOI:http://dx.doi.org/10.14195/2176-6436_26-2_13

Accessed : $\quad$ 26-Apr-2023 15:21:33

A navegação consulta e descarregamento dos títulos inseridos nas Bibliotecas Digitais UC Digitalis, UC Pombalina e UC Impactum, pressupõem a aceitação plena e sem reservas dos Termos e Condições de Uso destas Bibliotecas Digitais, disponíveis em https://digitalis.uc.pt/pt-pt/termos.

Conforme exposto nos referidos Termos e Condições de Uso, o descarregamento de títulos de acesso restrito requer uma licença válida de autorização devendo o utilizador aceder ao(s) documento(s) a partir de um endereço de IP da instituição detentora da supramencionada licença.

Ao utilizador é apenas permitido o descarregamento para uso pessoal, pelo que o emprego do(s) título(s) descarregado(s) para outro fim, designadamente comercial, carece de autorização do respetivo autor ou editor da obra.

Na medida em que todas as obras da UC Digitalis se encontram protegidas pelo Código do Direito de Autor e Direitos Conexos e demais legislação aplicável, toda a cópia, parcial ou total, deste documento, nos casos em que é legalmente admitida, deverá conter ou fazer-se acompanhar por este aviso.

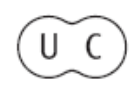




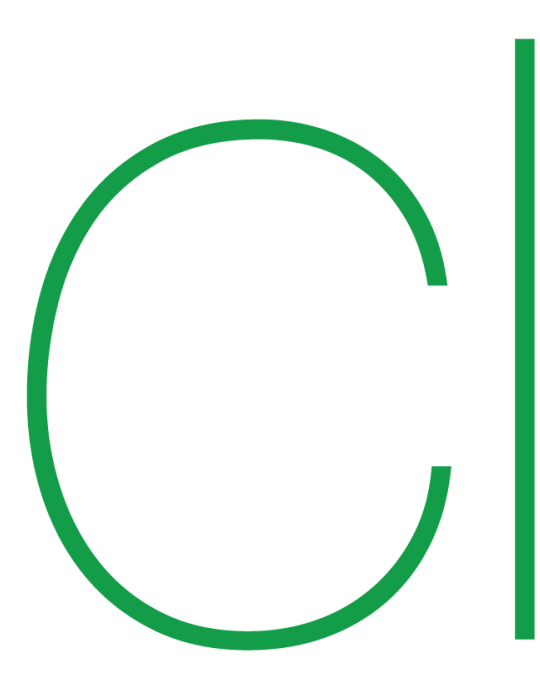

revista brasileira de estudos clássicos
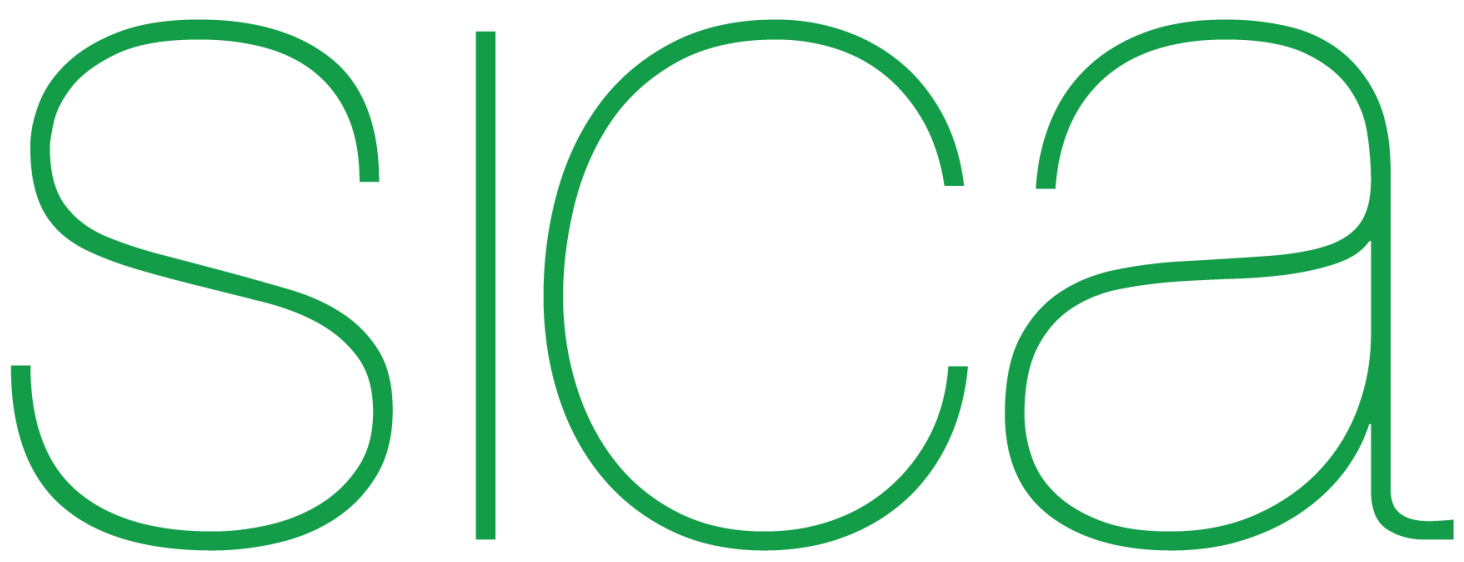

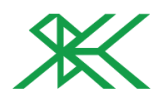

y

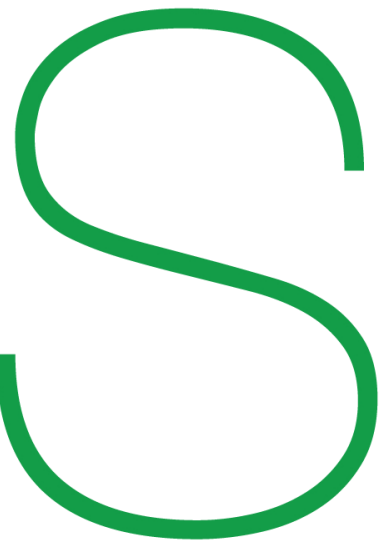




\section{FLORIO, R. (2011) TRANSFORMACIONES \\ DEL HÉROE Y EL VIAJE HEROICO EN EL PERISTEPHANON DE PRUDENCIO, BAHÍA \\ BLANCA, EDIUNS, PP. 267.}

Eleonora Tola*
*CONICET - UBA,

Argentina.

7 ansformaciones del héroe y el viaje heroico en el Peris-

tephanon de Prudencio (2011) es una segunda edición

del libro publicado en el año 2001. En ella se han introducido algunas correcciones de erratas, modificaciones estilísticas y observaciones a la luz de la bibliografía más reciente sobre el tema. R. Florio estudia los modos en que el cristianismo se apropia del género épico en ese texto de fines del siglo IV. Su análisis aborda, específicamente, el personaje central de la poesía épica clásica, el héroe, y el motivo concomitante del viaje heroico. Por un lado, se postula que el Peristephanon renueva el modelo heroico tradicional, dado que, a través de la figura del mártir que atraviesa sus catorce himnos, cristaliza con éxito el trasvasamiento operado por el cristianismo; por otro, que dicho trasvasamiento inaugura, a su vez, el tipo heroico vigente hasta la actualidad.

A partir del planteo de esas hipótesis en la Introducción (pp. XI-XXXV), es posible identificar tres líneas interpretativas complementarias en el tratamiento de los diversos aspectos de la obra: 1) La consideración del texto de Prudencio como emergente de un contexto socio-histórico, lo cual determina un acercamiento que no se limita a indagar la relación con sus modelos antiguos, sino que entiende cada una de sus expresiones en el marco de las expectativas de la época. De un modo general, esto supone una interrogación acerca de la actitud cristiana frente al desafío de construir un nuevo ethos sobre la base del sistema de creencias pagano; en particular, desemboca en una demostración de la finalidad sincrética de Prudencio en tanto exponente privilegiado de una dinámica cultural; 2) La postulación de la conquista de arquetipos como materialización de la conquista del Imperio a través de un doble movimiento de apropiación y renovación. La figura del héroe y el motivo del viaje heroico dejan al descubierto ese 
doble movimiento, en la medida en que la demarcación mayor se produce en el vaciado de esa matriz temática. En este sentido, R. Florio rastrea sus modificaciones a los efectos de aducir que éstas permiten leer el texto no solo como límite a muchos rasgos de la epopeya clásica, sino también como principio de una reelaboración integral del género; 3) La explicitación de la intención de Prudencio de promover una conversión espiritual y de la correspondiente reconversión literaria que operan sus himnos. Mediante un examen sutil de los mecanismos de tal reconversión, el libro de R. Florio despliega ambos planos del concepto, el espiritual y el genérico, para poner de manifiesto un doble proceso de conversión y fusión de la tradición pagana con la cristiana. La exposición de la problemática según esas tres líneas rectoras se organiza en cinco capítulos que ahondan distintas dimensiones del tema en cuestión (1. Continuidad y transformaciones, pp. 1-8; 2. Prudencio, pp. 9-65; 3. Viaje heroico: hasta y en Prudencio. Consideraciones generales, pp. 67-138; 4. Culto de los mártires, pp. 139-174; 5. El ideal heroico cristiano cristaliza en Prudencio, pp. 175-221). Dado que R. Florio explora múltiples aristas de igual importancia en lo que hace a la configuración del Peristephanon, creemos que, a la hora de delinear los principales rumbos de este estudio, resulta más interesante apuntar los trazos de una lectura acorde con un desarrollo que no procede de manera lineal, sino por niveles paralelos y confluyentes. Conforme a la imagen del complejo periplo heroico que se analiza, el texto mismo de R. Florio propone, pues, al lector, un recorrido a través de una vasta erudición en el manejo del tema y de sus relaciones intertextuales e interculturales. Simultáneamente, la fluidez de tal recorrido abre una vía de acceso cautivante incluso para un lector menos familiarizado con los mecanismos de la literatura tardoantigua. Referiremos entonces los rumbos de este libro en función de las líneas antes mencionadas, en torno a las cuales se articula la presentación de los mártires como paladines de la fe cuya obra culmina con la obtención de la recompensa de la corona.

En primer lugar, respecto de la obra de Prudencio como emergente de un contexto socio-histórico, R. Florio profundiza los factores que posibilitan la afirmación de una nueva perspectiva ontológica y la consecuente transformación del personaje heroico en pos de la figura de Cristo. La referencia a la temática del héroe y a la escatología estoica en el Sueño 
de Escipión ciceroniano, así como a su repercusión en la literatura cristiana y medieval (pp. 2-6, Cap. 1), esboza el tipo de abordaje que adopta R. Florio a lo largo de su libro. Éste trasciende, por un lado, una metodología meramente comparatista para centrarse en el entramado de resignificaciones que subyacen en el texto de Prudencio, entendido como referente literario de la conformación de la visión cristiana del mundo; por otro, expone un enfoque basado en la noción de arquetipo heroico en tanto coyuntura simbólica que se carga de nuevas valencias de acuerdo con el horizonte histórico y espiritual de la época. Al respecto, R. Florio no solo insiste en la conciencia de este autor acerca de su posicionamiento frente a los contenidos de la tradición clásica, sino también en ciertos rasgos estilísticos de una estética que debe ser comprendida a la luz de la evolución cultural de fines del siglo IV (pp. 12-28, Cap. 2). Los diversos aspectos del Peristephanon son estudiados, así, como síntesis entre la formación literaria clásica y la convicción espiritual de su autor, con especial hincapié en la percepción que tuvo Prudencio de ese momento de transición. Asimismo, se rastrean los modos en que construyó una obra que apunta a la transmisión persuasiva de los ideales cristianos, a través de una inclusión lúcida y activa de la tradición precedente en la dirección sugerida por el interrogante de Tertuliano: - ¿Cómo rechazar los estudios profanos, sin los cuales no podemos transmitir los divinos? II (p. 15, Cap. 2). Desde esta óptica de gradual transformación de las prácticas paganas, se refiere R. Florio a la configuración del héroe cristiano, a la nueva dimensión del concepto estoico de la passio y a su refundación como Gloria passionis en relación con los castigos previos a la muerte del mártir (pp. 23-33, Cap. 2).

En una misma línea interpretativa, el autor profundiza el tema del culto de los mártires como otro de los rasgos del arquetipo heroico, en la medida en que, desde los griegos, la posesión de un culto era uno de los principales signos de un héroe (pp. 139-145, Cap. 4). Dicho tema es vinculado con una serie de motivos concurrentes, como el del sepulcro, el de la conmemoración anual, el del carácter mediador del mártir, el de sus monumenta — en sus variadas manifestaciones- y el de la ceremonia de peregrinación al sepulcro. R. Florio parte de la inserción de estos componentes en una amplia tradición para subrayar, luego, la función que desempeñan los 
personajes de Prudencio tras su ascenso al cielo y puntualizar los rasgos de la compleja transustanciación de elementos de la religión antigua al cuerpo de creencias cristianas. En este sentido, la asociación culto-sepulcro en el himno 1 del Peristephanon permite ahondar la idea de la protección que ejercen los mártires para con su ciudad y constatar, a partir de allí, la emergencia de un nuevo elemento en el culto, a saber, la dimensión sagrada de las reliquias y su función de talismán protector (pp. 145-148; 151-156, Cap. 4). Al conjugar hábilmente el desciframiento del proyecto literario de Prudencio con las variables histórico-políticas de su surgimiento, R. Florio propone - a la luz de las profundas revisiones del sistema político imperial— una aguda interpretación de la afirmación localista subyacente en la particularización territorial de los mártires (pp. 157-161, Cap. 4).

Con respecto al análisis de las variantes con las cuales el texto presenta sus diversos rasgos heroicos, cabe destacar, por un lado, la lectura polifónica que lleva a cabo el autor entre el tema de la mediación o intercesión y el vínculo tradicional de patrón y cliente (pp. 148-151, Cap. 4); por otro, la relación del culto de los mártires con los antiguos dii patrii romanos a partir del apelativo patronus con el que Prudencio designa con frecuencia a sus personajes (p. 159, Cap. 4). La focalización de una perspectiva socio-cultural resulta, además, en una interesante conexión entre el tema del culto y el de la memoria a través del módulo culto-heroísmo-pasado (pp. 161-166, Cap. 4). Al tratarse de un recurso clásico efectivo para consolidar y mantener viva la gesta cristiana mediante el recuerdo de las pasadas vidas heroicas de los mártires, la memoria remite, en el nivel ideológico, a una \puesta en práctica de los mecanismos de la tradición como sistema diacrónico literario, continuamente articulado en sincrónicas reelaboraciones (p. 49, Cap. 2). La memoria se erige, así, en agente activo que, en distintos planos y desde el pasado, construye y vivifica el futuro. Desde este punto de vista se lee a las passiones, cuya integración en la liturgia a partir de su lectura pública actualiza el poder de Dios y transforma el culto de los mártires en - estructura de una memoria viva, en este caso bajo forma cristiana (p. 166, Cap. 4). En definitiva, R. Florio demuestra que el culto en tanto manifestación visible del plano de las creencias y sus elementos concomitantes fueron clave en el proceso que el 
cristianismo emprendió en la interioridad de las conciencias

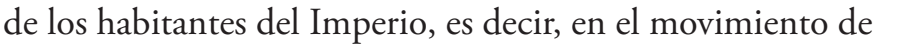
cristianización mental del mundo de ese tiempo (p. 161, Cap. 4), en el cual la nueva religión ya había afirmado su triunfo tras la superación de las primeras persecuciones.

En segundo lugar, respecto de la cuestión de la conquista de arquetipos a través de la figura del héroe y del motivo del viaje heroico, un estudio del entrelazamiento de sus alcances clásicos con los ingredientes cristianos le permite al autor delinear las etapas que culminan en la conformación de un nuevo género del tema del viaje. El análisis pone de manifiesto cómo la configuración del héroe cristiano se inscribe también en una disputa por la posesión de la conciencia, por la interpretación del pasado, en la medida en que el momento de enunciación del texto de Prudencio se sitúa en una época en la cual el cristianismo ya había infiltrado el poder político. A los efectos de desentrañar los mecanismos de transformación y construcción ética de los antiguos mitos relacionados con el motivo, R. Florio adopta una perspectiva de orden simbólico que se funda en la identificación e interpretación de una serie de imágenes que atraviesan los himnos y cuyo elemento articulador - puesto que da lugar al título de la obra- es la corona como intersección de tradiciones (pp. 26-28, Cap. 2). Tales imágenes operan en el Peristephanon la síntesis entre el antiguo arquetipo del héroe y el reciente repertorio de fieles inmolados bajo el emblema de la cruz. Cabe destacar la sutileza de una metodología que procede a partir del examen de los planos textual y contextual de diversos pasajes que exhiben, emblemáticamente, las etapas de los itinerarios simbólicos de los personajes (pp. 79-123, Cap. 3). En el marco de la idiosincrasia cristiana, el viaje adquiere rasgos de un apartamiento hacia la interioridad individual, de un camino hacia la salvación en el que cobra relevancia la dimensión espiritual del concepto de fortitudo, vinculada con un desplazamiento del combate con el enemigo externo a un combate más personal del mártir con sus propias flaquezas (pp. 69-73, Cap. 3). Desde esta óptica, y en tanto espejos de la nueva espiritualidad, los temas del antrum y del laberinto - y la imagen adyacente del bivium - despliegan simbólicamente los aspectos que hacen a la recreación prudenciana del viaje (pp. 91-112, Cap. 3). El entrecruzamiento de los planos diegético y simbólico 
del Peristephanon remite a elementos inherentes a los orígenes del cristianismo y al mismo tiempo evoca la dinámica genérica de este texto que funciona por apropiación y reelaboración, según emerge con claridad del análisis del paradigmático himno de Hipólito en el Capítulo 3.

En tercer lugar, en lo que hace a la intención de Prudencio de promover una conversión espiritual y a los correlatos estilísticos de dicha intención, el libro de R. Florio se centra en los diversos recursos con los cuales el cristianismo reconvirtió el modelo heroico de la cultura clásica. Se explora, particularmente, la materialización del nuevo arquetipo heroico en el plano expresivo y se señalan los mecanismos de la callida iunctura que realiza el Peristephanon entre ambas vertientes culturales. A su vez, el autor establece una sugestiva correspondencia entre la pluralidad de tradiciones que confluyen en el texto y el arte platónico de la poikilía (pp. 189-191, Cap. 5). Por un lado, se hace referencia a la función persuasiva del exemplum para poner de manifiesto la manera en que sus viejos contenidos son recreados en beneficio de los ideales heroicos cristianos. La modificación se vincula con el surgimiento de una nueva virtus, cuyos valores e implicancias morales equiparan a los mártires con los homines novi del antiguo sistema ético-político. Por otro lado, se estudian con especial atención dos planos estilísticos del Peristephanon: el de la apropiación del léxico a través de las formas de designación heroica (vir / heros) y el de las articulaciones del discurso a través de los símiles, recurso fundamental de la épica tradicional (pp. 191-201, Cap. 5). Por último, la asociación de las cualidades de los personajes de Prudencio con rasgos del poema de Lucrecio —entendido como eslabón en el proceso de renovación genérica- permite reconstruir el itinerario por el cual el mártir cristiano utiliza la palabra como el medio más eficaz para alcanzar la victoria y la apoteosis heroicas. El módulo lucreciano dictis non armis (5. 49-51) evoca un tipo de poema épico en el marco de un reencauce de los viejos soportes del género en favor de la nueva ideología. Respecto de la polémica caracterización genérica del texto lucreciano, la cual podría despertar ciertas objeciones en cuanto a la interpretación, R. Florio acota su objeto de investigación al posicionarse en un lugar que define la estructura compositiva de una epopeya en relación con el tipo de héroe que la protagoniza (p. 207, Cap. 5). En un mismo sentido, 
el autor sortea las dificultades que presenta el hecho de que el Peristephanon no se encuadre en el género épico desde el punto de vista de su construcción métrica, dado que no está escrito en hexámetros sino en versos más propios del diálogo y de la lírica. Sobre la base de apasionantes trabajos críticos, postula, pues, que ese plano del texto de Prudencio se inscribiría también en una dinámica de renovación que abarca los alcances de su ejecución métrica y se vincula, además, con la evolución de los metros hacia la rítmica acentual (pp. 27-28, Cap. 2). A partir del tratamiento de los distintos pliegues del Peristephanon a la luz de las líneas interpretativas señaladas, el libro de R. Florio exhibe, de manera rigurosa y amena a la vez, el sincretismo cultural que plantea el texto de Prudencio. Éste no supone una fractura respecto de la épica antigua, sino, por el contrario, una continuidad que garantiza la coherencia de la obra (pp. 223-236, Recapitulación y observaciones finales). R. Florio emplea una metodología que opera en segundo grado al estudiar el tema del héroe y del viaje heroico a través de una serie de itinerarios por las tramas estilística, simbólica e histórica del texto. Uno de los mayores méritos de tal metodología consiste, a nuestro entender, en que, además de contar con un sólido y erudito respaldo bibliográfico, construye gradualmente sus marcos teóricos a partir del avance de la problemática y no por fuera de él, según moldes preestablecidos. La teoría surge, así, del análisis, complementa y sustenta la profundización del concepto de interpretación' a lo largo del libro, en su doble dimensión de interpretación de la tradición genérica e interpretación de la cosmovisión clásica por parte del cristianismo. Por todo lo expuesto, no se trata solo de una valiosa contribución al estudio de la literatura tardoantigua, en general, y a la obra de Prudencio, en particular, sino también de un original abordaje polifónico que lleva a cabo, en su mismo desarrollo, una callida iunctura entre los diversos planos de estudio.

Recebido em novembro de 2012 Aprovado em fevereiro de 2013 